\title{
OS DOUS SAN MARTIÑO. \\ O PRIMER PATRÓN \\ E O PRIMER APÓSTOL DE GALICIA
}

\author{
Por \\ RAIMUNDO GARCÍA DOMÍNGUEZ \\ «BOROBÓ»
}

\author{
Ca lembranza de \\ D. Abelardo, D. Casimiro e D. Aquilino
}

\section{UN BURATO NEGRO NA NOSA HISTORIA}

Tres anos despois de que no 465 o monarca suevo Remismundo pasóuse co seu pobo do catolicismo ao arrianismo, fina o cronicón do Bispo Idacio, de Chaves, e xa non existen máis noticias do longo período arriano do Reino Suevo, ata que Juan de Biclara empeza a sua historia, coincidindo ca reconversión, no 559, do pobo suevo que retorna ao catolicismo co seu rei Teodomiro ao frente.

Nin San Isidoro na sua Historia Gothorum, Wandalorum e Sueborum, nin Jordanes na sua Romana e Gethica, din unha soia palabra de dito periodo; verdadeiro burato negro na Historia da antigua Galicia. Pois nada tratan tampoco del os outros historiadores que solían utilizar coma fontes. Así apenas se sabe, confusamente, o nome de catro monarcas suevos disa oscurísima etapa; nin que sucedéu nela.

«Nada sabemos de este período salvo los nombres de dos reyes dudosos: Teodemundo y Carriarico; del primero sólo se ha conservado el nom-

"CUADERNOS DE ESTUDIOS GALLEGOS", Tomo XLVI, Fascículo 111, Santiago 1999. 
bre en algún documento medieval; del segundo sólo hay referencia hecha por San Gregorio de Tours»; afirma o bonísimo sacerdote e historiador D. Casimiro Torres Rodríguez, na sua Galicia Sueva ${ }^{1}$.

Quizá podería mencionar tamén Don Casimiro ao «rey Deodiazca, del que sabemos por una moneda de época baja», citado así por D. Vicente Risco, na súa escueta e clara Historia de Galicia ${ }^{2}$. E parece raro que ao bo profesor Torres Rodríguez pasaralle desapercibida a «Introducción» que puso D. Paulino Pedret Casado, a sua versión De correctione rusticorum ${ }^{3}$, a obra máis mencionada de San Martiño Dumiense, publicada en Nos, cuarenta e cinco anos antes de que se imprimira a Galicia Sueva.

Pois ao falar D. Paulino daquel tempo (468 a 554) que eu chamo burato negro, dí que de todo ese período «só se coñece por unha inscripción recollida por Hubner o nome do rey suevo Veremundo (485)». Nome que o seu conveciño da rúa do Vilar, colega e amigo, ben poido añadir aos dos dous «reyes dudosos: Teodemundo e Carriarico». Os que xunto co citado por Risco, poderían formar unha baraxa de catro reixes suevos, cheos de misterio: Veremundo e Deodiazca, Teodemundo e Carriarico. Naipes pra arrastrar neste xogo histórico do burato negro da nosa época xermánica. Nise histórico momento é, precisamente, cando ao patriarca León de Jerusalén cúpolle enviar a sua arcana Epistola aos regibus francorum, et vandalorum, gotorum et romanorum notificándolles a traslación do Corpo do Apóstol Santiago as Hispanias e seu enterramento sub arcis marmoricis ${ }^{12}$.

\section{AS BRÁNDEAS DE SAN MARTIÑO}

Rómpese o enorme silencio histórico, xa nos amenes do arrianismo suevo, ca mencionada referencia de San Gregorio de Tours ao rei Carriarico; feita no seu libro sobre os Miraculis Sancti Martini. No que da noticia dun rei suevo ao que chama Kharrarico, quen tendo a seu fillo enfermo de lepra, e ao enterarse dos dons milagrosos do corpo de San Martiño, o Patrón das Galias, manda seus embaixadores a Tours, con moito ouro, para obter do santo a curación do seu heredeiro.

Non embargantes, retornaron seus mensaxeiros decíndolle que non curaría seu fillo ata que o pai «confesase a divinidade do Verbo». Entón o rei Kharrarico ordenóu labrar un templo en honor a San Martiño, pra

"CUADERNOS DE ESTUdIOS GALLEGOS", Tomo XLVI, Fascículo 111, Santiago 1999. 
albergar as reliquias que volvéu a pedir a Tours. Decindo que si merecía recibilas, creería canto predicaban os cregos católicos.

Logo o rei Kharrarico envióu de novo a seus embaixadores a Tours con grandes ofrendas pra que volvesen a pedir as reliquias do Santo $\mathrm{Pa}-$ trón das Galias. Chegados á tumba de San Martiño os enviados polo monarca suevo, lograron do Cabildo de Tours, según costume, as reliquias que solicitaban. Rogándolle inmediatamente: «Dadnos licencia pra poñerlas eiquí e tomalas mañán».

Ao concederlles permiso os coengos turolenses, tenderon os embaixadores de Kharrarico sobre o sepulcro de San Martiño de Tours un manto de seda e, despóis de bicalas, colocaron as reliquias encima dil, mentras decían: «Si atopamos gracia cerca do Santo Patrón, pesarán doble mañán, e serán postas pra bendición, buscadas pola fe».

Velaron toda aquela noite os criados do rei suevo, e a mañán volveron a pesar as reliquias, «e foi tanto a gracia do santo que subiron canto pudo mostrar a balanza».

Añade San Gregorio de Tours, no seu maravilloso relato, que «levantadas con gran triunfo as reliquias, chegando as voces dos que cantaban aos oidos dos encarcelados de ciudad, e admirando o suave daqueles sons, preguntaban aos guardias cal era a causa de tal xúbilo. Eles dixeron: Levan a Galicia as reliquias de San Martiño, e por iso son os himnos»; poñendo logo aos presos en liberdade.

«En qué consistían esas reliquias es lo que no se sabe -advirtéu don Manuel Murguía, nunha nota da sua Galicia-. Tal vez las constituían el velo o paño precioso que se extendió sobre el sepulcro del santo y al cual se creía dotado, por esto solo, de las virtudes que el sarcófago y restos que encerraba, tenían a los ojos de los fieles» ${ }^{4}$.

Esta opinión do «diligente Murguía» e a que moveu, posiblemente, a D. Casimiro Torres a poñer, a sua vez, na Galicia Sueva, a seguinte nota: «Estas reliquias eran lienzos, o paños, que se hubieran colocado sobre la tumba del santo y se llamaban brándeas» ${ }^{1}$.

Brándea (vocablo que falta tanto no diccionario da Real Academia Española e o de María Moliner, coma nos diccionarios galegos) é unha fermosa palabra litúrxica que denomina aos obxetos que estiveron en contacto cun corpo santo; establecéndose así unha clara diferenciación co puro concepto de reliquia, que tan soio consiste nun trozo daquel, xeralmente un oso.

"CUADERNOS DE ESTUDIOS GALLEGOS", Tomo XLVI, Fascículo 111, Santiago 1999. 


\section{NAVEGANDO CON VENTO PRÓSPERO}

No Panegírico de San Martín de Tours ${ }^{5}$, revelóu D. Marcelo Macías a seus fieles ointes a admirable actitud do santo no proceso, e frente a condena, de Prisciliano. E asimesmo narróu D. Marcelo, con grandilocuentes palabras, a conversión dise incerto rei arriano Kharrarico. Transcribía o sabio predicador da Capela Real, a versión que Menéndez Pelayo fixera do relato que San Gregorio de Tours escribéu sobre a prodixiosa conversión na sua obra De miraculis Sancti Martini Turonensis, publicada por Ruinart (París, 1699). Insertóuna D. Marcelino, no primer tomo da Historia de los Heterodoxos Españoles ${ }^{6}$, editado por vez primeira en 1880, once anos antes do histórico sermón de D. Marcelo.

Ten o relato de San Gregorio Turonense «cierto sabor de piadosa leyenda, que perdería traducido en el árido estilo de nuestra historia», señalaba Menéndez Pelayo. E, en efecto, traduce «la hermosa tradición que en el siglo VI explicaba el súbito tornar de los suevos al catolicismo», dun modo tan poético e belido que tan excelente latinista coma foi o gran mestre de Risco e Otero Pedrayo, o utiliza no seu panexírico, sin enmendar nin citar a versión de D. Marcelino.

En cámbeo, máis tarde, D. Casimiro Torres, tamén bo latinista, si que cita e calca na Galicia Sueva, ao autor da Historia de los heterodoxos: «veamos las palabras de San Gregorio de Tours, y para evitar toda sospecha de tergiversación -advierte-, reproducimos la versión hecha por Menéndez y Pelayo, que por otra parte es correcta y elegante» ${ }^{1}$.

Transcribiréi aquí tamén o párrafo no que San Gregorio conta como viñeron polo mar a nosa terra aquelas reliquias, ou brándeas, de San Martiño Turonense, tal como o escribéu D. Marcelino en castelán: «Y entre acciones de gracias, navegando con viento próspero, so el amparo celeste, mansas las ondas, reposados los vientos, pendientes las velas, tranquilo el mar, aportaron felizmente en Galicia» ${ }^{6}$.

Unhas palabras moi semellantes leeríanse, nada menos que seis séculos despóis, no trasunto da misteriosa o pseudo Epístola do Papa León, xa aludida, que aparece no libro terceiro do Codex Calixtinus ${ }^{7}$, ao narrar a traslación marítima do Corpo do Apóstol Santiago, levado por seu discípulos: «Hinchadas las velas por vientos favorables, navegaron sobre las olas del mar, llegando al puerto de Iria, alabando la clemencia de nuestro Salvador» (traducción ao español, do profesor Julio Feo).

"CUADERNOS DE ESTUDIOS GALLEGOS", Tomo XLVI, Fascículo 111, Santiago 1999. 
Esta semellanza ainda se acrecenta na lección do mestre Panicha, incluida no mesmo Codex, na que versifica unha versión máis antigua de enigmática Epístola, trasposta deste xeito, en versos casteláns, por D. Abelardo Moralejo:

Esta nave con carga tan sagrada, Por la divina mano gobernada, Al puerto de Iria llega por las olas, En las últimas playas españolas. Con días de bonanzas navegando. Salmos e himnos proféticos cantando, Al séptimo, bañado en luz y unción, Descansan en el puerto de Padrón.

Sospeitase, pois, unha anticipación da leenda xacobea na vella vinculación do Patrón das Galias con Galicia, ca chegada das suas brándeas a nosa terra e o culto que aquí se lle rindéu en Ourense e en tantas outras antiguas parroquias. Non deixóu de aproveitar o clérigo poitevino, Americo Picaud, no Codex Calixtinus, aquil material suministrado polo Bispo Gregorio de Tours, seis séculos denantes, como aproveitaría tamén os versos latinos do seu propio e antigo Bispo de Poitiers, San Venancio Fortunato, en alabanza de seu amigo San Martiño Dumiense, pra usalos e modificalos en honor e gloria do Apóstol Santiago.

\section{OS NOMES DO REI KHARRARICO}

Aquelas reliquias, ou brándeas, de San Martiño de Tours foron depositadas nunha iglesia de maravillosa construcción, miroque opera-escribe San Gregorio Turonense-, mandada edificar por aquel rei Kharrarico, que acaso foi a primitiva catedral de Ourense, cuio emplazamento discuten os arqueólogos.

Alí ocurriría o prodixioso feito narrado tamén no libro De Miraculi Sancti Martini Turonensi, inserto no tomo XVII da España Sagrada, do Padre Flórez. De ahí tomóu o relato dese milagro D. Marcelo Macías, para incluílo no seu Panegírico de San Martin de Tours ${ }^{5}$, ao falar de «Miro, el piadoso monarca en cuyo reinado obró San Martín el nuevo prodigio

"CUADERNOS DE ESTUDIOS GALLEGOS", Tomo XLVI, Fascículo 111, Santiago 1999. 
de secar, primero, y sanar después, la mano de un bufón que, contra el mandato del rey, osó alargarla a las uvas de un emparrado que sombreaba la entrada del templo erigido por Charrarrico».

Contóulle este milagro ao bispo Gregorio de Tours, un embaixador de Francia chamado Florenciano, que estivera na corte do rei Miro, e oírao da boca do propio monarca. Gregorio Turonense informa ademáis que «erat enim eo tempore Miro Rex in civitate illa in qua decesor eins basilicam sancti Martini aedificaverat». Ou sexa (asegún traduce D. Casimiro Torres, na Galicia Sueva) que «era a la sazón Mirón rey en aquella ciudad en la que su antecesor había edificado la basílica de San Martín». Sendo así, probablemente, Ourense, a corte onde permanecéu certo tempo Florenciano, aquel embaixador do rei de Francia.

Pois ben, si o predecesor do rei Miro no trono suevo foi o constructor da basílica de San Martín, tal coma indicaba San Gregorio de Tours haberá que deducir que ese rei Miro ou Mirón sería o sucesor de aquel Kharrarico; cuio nome o mencionóu de este xeito, o santo historiador dos francos.

Logo lle chamarían «Charrarico» Menéndez Pelayo, Marcelo Macías e Vicente Risco; «Carriarico» Ángel del Castillo, Aguado Bleye e Casimiro Torres; «Carriarick» Manuel Murguía, e «Carrarico» tamén don Casimiro. Esta curiosa diversidad atopeina entre os autores que o citan e que manexéi. De ahí que non repita eu sempre ese nome, posiblemente de raigambre merovingia, ca misma ortografía.

Tendo en conta que como confirma o Biclarense «in provincia Gallaecia Miro post Theodomirum sueborum rex efficitur» (na provincia de Galicia Mirón despois de Teodomiro é proclamado rei dos suevos), pode identificarse a Kharrarico co rei Theodomiro. Quén, pra maior lio, denantes de ser bautizado, chamábase Ariamiro.

Nesta identificación parecen estar conformes moitos historiadores, tales como Ruinart, Baronio, Masdeu, Schmidt, Menéndez Pelayo, D. Marcelo e o bó de D. Casimiro. «Sin embargo -escribe este último- existen otros de gran prestigio como Flórez, Murguía y Reinhart, que no admiten tal identificación y por tanto opinan que hubo dos conversiones de los suevos, aparte la de Reckiario: una en el reinado de Carriarico y otra en la de Teodomiro» ${ }^{1}$. 


\section{O NOVO SAN MARTIÑO}

Dado que a sucesión hereditaria era o normal na corona sueva, o lóxico sería que o rei Miro fose fillo do inconcreto monarca Kharrarico / Ariamiro / Theodomiro. De ser así podería tratarse do mesmo príncipe enfermo de lepra, cuia milagrosa curación propicióu a reconversión do pobo suevo ao catolicismo.

Explicaríase de ese xeito, máis dramáticamente, o motivo da íntima amistad, propia do discípulo co mestre, que sempre existiría entre o probable príncipe Mirón, prodixiosamente curado do mal de San Lázaro, e o monxe Martiño; quen, no momento histórico en que «aportaron felizmente a Galicia» as reliquias do Patrón das Galias «chegóu tamén de lonxanas terras, movido pola divina inspiración», como apuntóu ademáis Gregorio Turonense.

Poideron coincidir así, no indeterminado porto galego onde desembarcaron as anceiadas reliquias, o fillo do rei e o futuro San Martiño Dumiense. Ese encontro poido ocurrir arredor do 550. Este Martiño, chamado despóis Dumiense, oriundo ${ }^{8}$, igual que seu tocaio e precursor San Martiño de Tours, da provincia romana da Panonia superior, correspondente a actual Hungria.

Ainda que moi distante no espacio, a Panonia tiña certas afinidades con Galicia, pois fora poblada por tribus celtas, pronto romanizadas, e logo ocupada, no século IV, por os cuadosuevos. Todos os cuados eran suevos, mais non todos os suevos eran cuados. E parece ser que foron hordas de esta rama sueva as que tamén invadiron e dominaron Galicia, no segundo decenio do século V.

Cento cuarenta anos máis tarde chega a noso país ese monxe oriundo de Panonia, asimesmo Martiño de nome, por cuias venas podería correr sangre celta ou sueva, mezclada ca romana ${ }^{9}$. Asegún D. Casimiro «es posible que hablase el idioma germánico de los suevos y el latín, de modo parecido a como ocurría en la Galicia de su tiempo» ${ }^{1}$. Esta circunstancia faría máis idóneo ao novo Martiño pra seu apostolado na Galicia dos suevos; pois podería falar e entender aos dominadores xermánicos na sua propia lingua.

A biografía máis escueta e cabal que se fixo da etapa galaica de San Martiño Dumiense escribéuna o entón xoven sacerdote galeguista, Paulino Pedret Casado, na Introducción a sua mencionada «Traducción galega da 
obra de San Martiño de Braga De correctione rusticorum». E tan breve que ben cabe aquí:

«Dende arredor do ano 550 ata o 580 desenrólase no reino suevo a actividade d-un santo esgrevio na cencia e cheo de prestixio, San Martiño de Braga. Nado n-a Panonia viñera a esta nosa terra de tanta sona entre os ascetas occidentaes xa do século IV. Eiquí erguéu o mosteiro de Dumio, preto de Braga, capital dos suevos, e dende alí infruéu na conversión d-istes xermáns. Probabremente denantes do ascenso de Teodomiro ou Ariamiro ao trono foi instituido bispo de Dumio e como tal asistéu ao primeiro concilio de Braga (561). No segundo concilio d-iste nome xa o atopamos de metropolitán da cibdade capital dos suevos. No ano 580 morréu chorado pol-o pobo e a sua festa celébrase o 20 de marzo como consta nos Breviarios antigos das Eirexas de Braga e de Évora»${ }^{3}$.

Non, por certo, no día once de noviembre, ou de Santos, popular e antiquísima festa de San Martiño de Tours, «cuando los orensanos celebran las primicias de las castañas y del vino nuevo»; coma escribe Otero Pedrayo no seu épico Ensayo histórico sobre la cultura gallega. Onde o señor de Trasalba, arrastrado polo inmenso caudal do seu vocabulario e grandilocuencia, parece fundir, ou confundir, aos dous santos tocaios e coterréneos. Confusión moi común, acrecentada polo fervor que o Dumiense puso no culto ao Turonense.

Así ao falar da Festa de San Martiño, dí alí D. Ramón Otero que «de los pinares, de las huertas, y viñas, de las colinas peñascosas y soleadas suben columnas de humo azul, como de sacrificio pagano. La fiesta popular conserva un inconsciente simbolismo, pues San Martín no sólo convirtió al catolicismo la fiera gente sueva, sino que extirpó, en todo lo posible, los recuerdos de la religión celta y de las gnosis priscilianistas. San Martín, catequizó definitivamente a Galicia. Todo lo definitivamente a que puede ser sometido el radical panteismo de un pueblo celta» ${ }^{10}$.

E iste San Martiño catequizador foi, evidentemente, o Dumiense, o de Braga, non o de Tours. Quén no seu tratado De correctione rusticorum tratóu de atallar a persistencia na católica, agraria e sueva Galicia, os ritos e supersticións pagáns daquel pobo radicalmente castreño, que os homes de Nos ainda consideraban vagamente celta. 


\section{O PRIMER PATRÓN E O PRIMER APÓSTOL}

Supoñía Pedret que o novo Martiño «foi instituido bispo de Dumio... denantes do ascenso de Teodomiro ou Ariamiro ao trono». Si foi así o Kharrarico que reinaba cando chegóu o novo crego panonio ao mesmo tempo que as reliquias, ou brándeas, do Patrón das Galias, sería un monarca distinto e inmediatamente anterior a Teodomiro. E acaso éste fose $o$ fillo dil, que adolecía do mal de San Lázaro, curado por aquélas. E non Miro, ou Mirón, que nese caso sería neto de Kharrarico. Pudendo conciliarse así este parentesco ca afirmación de Gregorio Turonense, xa citada, de que o seu antecesor edificara a basilica de San Martín. Pois antecesor pode ser o abó, xa que non predecesor, suxeto que sería, sin dubida, o rei Teodomiro, pai de Miro, o monarca discípulo de San Martiño Dumiense.

Chegara este novo Martiño á terra galaica século e medio despóis de que morrera en Tours, a finales do IV, o seu paisán e homónimo panonio xa santificado. Emerxéu, pois, ao final do tenebroso periodo, que inda e o burato negro da nosa historia, unha luminosa figura que exercéu un auténtico patronazgo espiritual mentras duróu aquí o reino dos suevos.

Foi Martiño o de Dumio un varón de carne e oso, nada fantasmal, que tuvo a sorte ou o destino dun apóstol. Dun verdadeiro Apóstol dos galegos, casi tres séculos denantes da Invención da Tumba do Apóstol Santiago. Por elo o cantóu San Venancio Fortunato, o derradeiro poeta romano, bispo de Poitiers: «Martiño servata novo Galicia, plaude. Sorti Apostolicae vir tuus iste fuit» (Galicia reservada ao novo Martín, aplaude; iste varón teu tivo a sorte dun Apóstol) ${ }^{11}$.

Veu San Martiño de Braga a vivificar, en certo modo, a dar corporeidad na Galicia, ao maravilloso e sepulcral mito de San Martiño de Tours, patrón das Galias. E así ben se manifestóu nos inspirados versos que compoñía o seu canto adicado a él, inscritos na fachada sur daquel templo auriense, miroque opere, edificado polo rei Karrarico. Loaba Martiño Dumiense a fama, a influencia espiritual do Martiño Turonense, que se extendía dende «os paises árticos situados na extremidad do mundo», ata a toda Galicia que o tería por Patrón:

"CUADERNOS DE ESTUDIOS GALLEGOS", Tomo XLVI, Fascículo 111, Santiago 1999. 


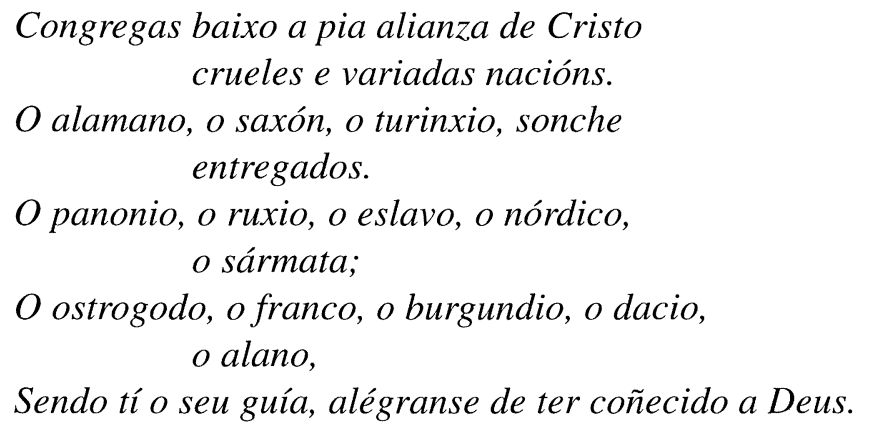

Ista relación de xentes europeas convertidas ao cristianismo, únicamente poido ser superado despóis pola célebre lista de pobos pelegríns que o Papa Calixto daría no sermón da Traslación de Santiago Apóstol, que figura no seu Codex ${ }^{7}$. Son exactamente setenta e catro os pobos de tal nómina calixtina, mentras que son soio trece as «crueles e variadas nacións» que guiadas por San Martín de Tours alegrábanse de coñecer ao Sumo Facedor.

Restaba por mencionar ao prelado e poeta panonio/dumiense, nos seus versos do hastial catedralicio auriense, o prodixioso motivo que induxo a outra nación máis, a sueva, a arder tamén «co fogo encendido do divino espirito». O maravilloso motivo foi a causa de que se edificara aquel templo, onde exteriormente se inscribían tales versos:
Admirando teus prodixios o suevo aprendéu, A senda da fe por onde camiña, $E$ devoto a teus méritos, levantando nestos adros un suntuoso edificio, Construéu un templo venerable de Cristo.

Non fai falta repetir que o suevo que o edificóu foi Kharrarico, quen con seu heredeiro, sua corte e pronto todo o pobo gali-suevo, volve ao catolicismo, abandonando pra sempre o arrianismo, merced a milagrosa influencia de San Martiño de Tours. O cal inspira ao Dumiense seus postreros versos da basilical fachada, dirixíndose a seu santo e homónimo paisán. A quén fala en nome do pobo gali-suevo: 
... que seguro, Martín,

Da gracia evidente dos teus milagros,

Suplicache que atendas seus rogos;

E así como a Galia gozosa tente

Como pastor preferido e propio,

Toda a Galicia te teña por Patrón.

Estos piadosos versos, mal traducidos por mín á lingua vulgar, proclaman de esa maneira o patrocinio celestial da Gallecia, exercida polo Patrón das Galias, durante tres séculos, antes de que esa misión lle correspondera a Santiago Apóstol. Pois vai dende mediados do século VI hasta a coarta década do IX, en que foi descuberto o sepulcro do que sería definitivo Patrón de Galicia e de España; de acordo cos cálculos cronolóxicos xacobeos do exactismo historiador López Alsina ${ }^{12}$.

Polo tanto cabe afirmar que ao longo de aqueles trescentos anos foi San Martiño de Tours Santo Patrón de Galicia, mentras que San Martín Dumiense foi o Apóstol dos galegos durante os trinta anos que vivéu entre eles.

Tal etapa histórica do patronazgo dos galegos por San Martiño de Tours, na que proliferan os templos parroquiales e cenobios consagrados a este santo, comprendéu o periodo final do Reino Suevo, o da hexemonía visigoda e os anos iniciaes da invasión árabe, ata que se consolida o Reino Asturiano, que fai do Fillo do trono seu santo adalid frente aos mahometanos.

\section{AS NOTICIAS DE SAN GREGORIO DE TOURS}

A través das rutas marítimas ou terrestres que existían entre as Galias e Galicia xa no século VI, debe haber unha frecuente comunicación entre as diócesis de Tours e de Braga, que permitéu ao bispo turonense e historiador dos francos, San Gregorio, poseer un evidente coñecemento da vida e virtudes do asimesmo santo arzobispo bracarense, Martiño de Dumio.

Reflexa ese coñecimento San Gregorio de Tours nos dous célebres libros que compoñen toda a sua obra, Gregori Episcopi Turonensis Opera Omnia. O primeiro constitue a Historia Francorum, que é o funda-

"CUADERNOS DE ESTUDIOS GALLEGOS", Tomo XLVI, Fascículo 111, Santiago 1999. 
mental testimonio histórico da Francia merovingia. O segundo, denominado Miracula e Opera Minora, ven a ser, especialmente, unha maravillosa serie haxiográfica.

De tal Opera Omnia fixo Ruinart unha edición no ano 1699, en Luteciae Parisorium, un belido modo de nombrar Paris. Foi a que manexóu Menéndez Pelayo ao escribir seus Heterodoxos ${ }^{6}$, polo 1880; pois ainda non poido utilizar a impresa en Hannover, no 1895, que coa rúbrica de Scriptores Rerum Morovingiacarum, forma parte da Monumental Germaniae Histórica, editada por Mommsen.

Entre os Miraculi e Opera Minora, de Gregorio de Tours, se atopa a haxiografía titulada De miraculis Sti. Martini; un dos cales e o da curación do fillo do rei Kharrarico. E ainda que estos milagros relatados por San Gregorio perteñecen a seu glorioso antecesor na mitra turonense, proporciona nese opúsculo os maiores datos que se saben acerca da procedencia e educación de San Martiño Dumiense.

Por si fora pouco, refirese ao novo Martiño repetidas veces na Historia Francorum. Dando conta, por exemplo, da sua chegada a Galicia, cara o 550, e da sua morte no 580, atestiguandoa con estas palabras: «Neste tempo morréu o benaventurado Martiño, bispo de Galicia, e seu pobo desbordóuse en planto».

Tanto pra escribir a milagrosa leenda que dou motivo ao patrocinio celestial dos galegos por San Martiño de Tours, como pra dar noticias moi concretas sobre San Martiño de Braga, o prelado e historiador turonense tivo que ser informado por os viaxeiros procedentes do Reino suevo, ou polos que iban e viñan; como aquel embaixador dos francos na corte sueva, chamado Lorenciano, que lle contóu o milagro do bufón do rei.

\section{OS VERSOS DE SAN VENANCIO DE POITIERS}

$\mathrm{Na}$ Galia dominada polos francos, unha xeneración episcopal de ilustrísimos escritores asegura a persistencia das letras latinas, cultivando especialmente a historia da sua época e a poesía relixiosa. A sua figura señera, ademáis de San Gregorio, bispo de Tours, foi o xa dito «último poeta romano», San Venancio Fortunato (entre 530-600), bispo de Poitiers. 
Ambos prelados da Galia mantiveron unha extraordinaria vinculación co seu colega San Martiño, arzobispo de Braga. Mercede a seus escritos pode saberse o esencial da vida eo espíritu deste Santo varón. Parece, en principio, asombroso, que en pleno apoxeo das invasións xermánicas quepa poseer un coñecemento tan preciso da existencia dun bispo que pastorea no confín occidental da Cristiandad, por parte de outros máis centrados en Europa.

Anque habería que esclarecer si existéu ou non un trato persoal entre un e outros, cabe imaxinar, non embargantes, que o monxe Martiño poido coincidir con San Venancio e tamén con San Gregorio nun lugar indeterminado, onde cecáis despertóuse a simpatía e admiración polo arzobispo bracarense que pronto mostrarían os bispos dos francos nas suas respectivas obras.

Pra aclaralo terían que seguirse ao dedillo as hagiografías de tales bispos da Galia, co fin de averiguar si Gregorio Turonense ou Venancio Fortunato estiveron en Bizancio o en Palestina, durante o tempo en que o monxe Martiño ampliaba alí os seus estudios filosóficos e teolóxicos. Si ben cabe pensar ainda que o futuro Dumiense, en vez de vir directamente a Galicia, pola vía marítima do Mediterráneo e o Atlántico, pasase antes algunha temporada en Italia ou en Francia. Onde poido facer amistade, en calquera das suas ciudades ou mosteiros, cos daquela xóvenes sacerdotes que tanto brillo darían as letras latino-cristianas.

Sabemos que Venancio Fortunato nacéu en Treviso, localidad do norte de Italia, e que se educou en Rávena ${ }^{13}$. Peregrinando polos Alpes e a Xermania chegóu á Galia, fixando a sua morada en Poitiers, a rogos de Santa Radegunda, viuda do rei merovinxio Clotario I. Alí ordenouse presbítero e foi preconizado bispo. Compuso once libros de poemas, cartas e exposicións, e tamén unha vida de San Martiño de Tours.

E asimesmo o fermoso Carmen adicado a San Martiño Dumiense que figura no libro V da sua obra poética (Venanti Honori Clementiani Fortunati liber quintus, II). Pondera alí o bispo italiano de Poitiers as cualidades de dulzura, claridad, virtud e sabiduría de San Martiño de Braga. Prefire leer suas obras, máis espontáneas que as de Cicerón e de Virxilio, máis asequibles que as de Platón e Aristóteles; e máis sinxelas que as de Hilario, Gregorio, Ambrosio ou Agustín (asegún resuméu D. Casimiro $^{1}$, sin dar aos últimos tratamento de santos).

"CUADERNOS DE ESTUDIOS GALLEGOS", Tomo XLVI, Fascículo 111, Santiago 1999. 
O bispo poeta de Poitiers seguramente leera moito máis versos e versículos do Dumiense dos que chegaron a ser publicados na Edad Moderna. Apareceron éstos primeiro na Máxima Bibliotheca Veterum Patrum (Lughni, 1677); logo Simond, o P. Flórez e Migne, na sua Patrología, volveron a editalos.

\section{A SORTE DUN APÓSTOL}

O Carmen de Venancio Fortunato consagrado a San Martiño de Braga vai precedido dunha carta, en estilo retorcido, con esta adicatoria: «Ad Martinum Episcopum Galliciae. Domno, sancto atque Apostolico in Christi regis exercitu postducem Paulum primipilo, Martino Episcopo Fortunatus».

Alude eiquí San Venancio, asegún varios comentaristas, a creencia no apostolado de San Pablo en España -explica D. Abelardo Moralejo, nun revelador artigo do Compostellanum-, «ya que llama a San Martín capitán de la primera compañía detrás del jefe Pablo, en el ejército de Cristo Rey, y no parece que haya otra explicación».

Logo Venancio Fortunato inicia seu Carmen tratando, precisamente, da distribución dos apóstoles na predicación da boa nova polas distintas nacións: «Roma cayó en suerte a Pedro, Iliria a Pablo, Etiopía a Mateo, Persia a Tomás, la India a Bartolomé y Grecia a Andrés, sin decir una palabra de los otros Apóstoles, Juan, Santiago el Menor, Simón, Felipe, Judas Tadeo y Matías» (resume así o P. García Villada, na sua Historia eclesiástica de España).

Contando a San Pablo son trece os apóstoles. Faltaría, pois, Santiago o Maior nesta lista. Ausencia que foi ponderada polo P. Duchesne no seu moi trascendental e controvertido artigo sobre Saint Jacques en Galice (nos Annales du Midi, Toulouse, 1900), que resalta o papel atribuido no poema de Venancio Fortunato aos santos Martiño de Tours e de Braga. Veñen a señalao deseguida os versos do bispo poitevino:

«Ne mores accelerans, Martini Galia prisci. Excellente fidi luminis arma capit. Martino servata novo, Gallicia, plaude. Sorti Apostolicae vir tuus iste fuit».

"CUADERNOS DE ESTUdIOS GALLEGOS", Tomo XLVI, Fascículo 111, Santiago 1999. 
Que o Dr. Moralejo e seu ilustre discípulo D. Casimiro han de traducir así ao español: «Acelerando sin demora, la Galicia recibe las armas de la luz por medio de la fe luminosa del primer Martín; Galicia reservada al nuevo Martín, aplaude; este varón tuyo ha tenido el destino de un Apóstol».

Os tres vocablos «ne mores accelerans», acelerando sin demora ${ }^{15}$, marcan, sin duda, no Carmen consagrado ao Dumiense -asegún D. Abelardo- una transición del plano de los apóstoles por antonomasia, tras haber mencionado a seis de ellos, al de los apóstoles posteriores, los dos Martines de Galia y de Galicia, a quienes el poeta relaciona por su nombre, su patria, su origen, etc.».

Esa transición, non fora advertida por Mons. Duchesne, no seu tan polémico, por antixacobeo, artigo finesecular (xa que foi publicado no derradeiro ano do século XIX, ou sexa o ano 1900). Ao non tela en conta, fixo que os San Martiño foran para il apóstoles cos mesmos títulos que os da media ducia citados diante.

O que no Carmen non se mencionara entre os apóstoles a Santiago Zebedeo, «lo que más puede significar -explicaba o Dr. Moralejo- es ignorancia respecto de apostolados anteriores en Galicia por parte de Fortunato, o exaltación, retórica tal vez», do apostolado galaico de seu coetáneo San Martiño de Dumio.

Galicia foi salvada polo Dumiense, sendo en salud dos galisuevos: Est magis effectus Gallisueba salus. Esto é o que canta Venancio Fortunato, e parece bastante ao sabio latinista don Abelardo; quen precavidamente, advirte, que non se pode usar elo coma testimonio contrario a leenda da predicación do Apóstol Santiago na Península Ibérica.

\section{O PLAXIO APOSTÓLICO}

Venancio Fortunato prosigue no dístico seguinte ao de «ne mores accelerans» a exaltación poética de San Martiño Dumiense, decindo que «lle ofrecia a Galicia a virtude de Pedro, a doctrina de Pablo e a axuda de Santiago e de Xoán». Qui virtuti Petrum praebet tibi, dogmate Paulum, hine Jiacobi tribuens, inde Ioahannis opem.

No caso de que o Santiago citado por San Venancio fose o Maior sería a única referencia que existe no seu Carmen ao Fillo do Zebedeo, sin que 
fixese ningunha alusión a que éste precedera a San Martiño na evanxelización das xentes galaicas.

Logo o bispo de Poitiers exalta ao de Braga «como taumaturgo de los Galli-Suevos en versos llenos de dulces imágenes de cosechas y arboladas», cal di Otero Pedrayo no mencionado Ensayo seu ${ }^{10}$. Son os catorce dísticos onde Venancio Fortunato canta que Galicia lle correspondéu coma heredade ao Dumiense louvado...

... pra traballar no seu apostolado

Que estirpóu a maleza e a amarga cizaña,

E nas ramas da herexía fincóu pugas pías da fe

E o que era oleastro ${ }^{16}$ rebrota pingüe oliveira.

A laida figueira, condenada ao lume sin remedio,

Disposta a dar fruto no seu seno, de esterco ben nutrida.

Os acios, revinchando nas videiras, pra pasto dos paxaros,

co tal gardián o bo lagar non a marrará.

Pois limpando o campo de fronzas, trocou as espiñas en racimos ${ }^{17}$.

Constituie unha pasmosa sorpresa topar estos catorce dísticos de Venancio Fortunato, en louvanza de seu coetáneo Dumiense, formando parte do «Sermón del Santo Papa Calixto en la Pasión de Santiago Apóstol que se celebra el día 25 de julio», incluido no capítulo VI do Libro I do Codex Calixtinus ${ }^{7}$. Neste sermón, o suposto Pontífice cluniacense recita as «virtudes e predicacións» do Apóstol Santiago, cantadas por «San Fortunato, poeta distinguido, confesor de Cristo e bispo».

Pois ben neste centón poético de vinteoito dísticos elexíacos compostos por Venancio Fortunato, seus versos, desde o que fai o $\mathrm{n}^{\circ} 15$ ao 28 , ambos inclusive, foron tomados ao pe da letra do mencionado Carmen que o bispo de Poitiers consagróu Ad Martinum Episcopum Galliciae (Carmina III) no século VI. Esta procedencia foi localizada polo sabio filólogo Dr. Moralejo Laso, coma consecuencia da sua traducción ao español do Liber Sancti Jacobi, que motivou os seus traballos posteriores a propósito das fontes literarias desa fantástica e piadosa obra. Primeiramente tratóu delo en seu artigo sobre Las citas poéticas de S. Fortunato en el Codice Calixtino $^{18}$ e logo no seu citado opúsculo.

As citas poéticas de $\mathrm{S}$. Fortunato no Codex Calixtinus son oito ou nove, con cento cincoenta versos en total. E don Abelardo localizóu cento 
carenta delas, pudendo «comprobar que las citas son efectivamente centones formados con partes de diversos poemas, desde dísticos y versos sueltos hasta grupos de dísticos seguidos, y que, además, tienen alteraciones e interpolaciones para acomodarlos a su nuevo fin de dar autoridad a la compilación en honor de Santiago con el nombre del ilustre poeta y obispo de Poitiers». Aparecen os versos de Venancio Fortunato tanto no libro I do Codex, dentro dos sermóns chamados pseudo-calixtinus, coma no libro IV. Ou sexa na fantástica Historia Karoli Magni, ou Historia Turpini ${ }^{7}$.

Mención especial merece o poema De Virginitate, de S. Fortunato, adulterado ao reproducilo no Codex Calixtinus (libro I, capítulo II); onde tamén se especifica a distribución dos apóstoles polas suas correspondentes terras de evanxelización. Ainda que de maneira mais completa e algo distinta que na lista dada no Carmen consagrado ao Dumiense. Pois figuran nesta outra relación cinco apóstoles máis de Cristo, e varíase a ubicación de Santo Tomás; pois pasa de Persia a Edesa. Sin que no poema orixinal de Venancio Fortunato se fixera tampouco a menor alusión a Santiago o Maior coma evanxelizador de Galicia.

Nembargantes, o máis peregrino é que intercalara o compilador do Codex no centón De Virginitate un novo dístico, seguramente da sua invención, pra introducir nel a mención do noso Apóstol Santiago. Dí así: «O que lembran as xentes, Santiago o de Zebedeo. Dende o pais galego as estrelas sube» ${ }^{7}$. Hai un eco neste segundo verso, sen dubida, da prodixiosa traslación aérea do Apóstol, dende Padrón ao Libredón, que consta nas versións máis antigas da Epistola Leonis ${ }^{12}$.

\section{AS MIXTIFICACIÓNS DO CREGO POITEVINO}

Acerca do probable autor destas mixtificacións dos versos orixinais de Venancio Fortunato, aproveitándoos en louvanza de Santiago Apóstol, tratéi longamente nos anacos do meu novelo, publicados en La Región, durante a Gran Perdonanza de 1993. Alí resumín os estudios e as suposicións de Vázquez de Parga e do propio Dr. Moralejo sobre a misteriosa personalidade do compilador do Codex Calixtinus.

Así Vázquez de Parga, na sua copiadísima e insuperada obra sobre Las peregrinaciones a Santiago de Compostela, indica que unha lectura seguida do Liber Sancti Jacobi, ou sexa o célebre Codex Calixtinus, «con-

"CUADERNOS DE ESTUDIOS GALLEGOS", Tomo XLVI, Fascículo 111, Santiago 1999. 
vence fácilmente de que cualquiera que sea el remoto origen de muchas de las piezas heterogéneas que lo componen, todas ellas han sido repasadas y arregladas por una persona en la que todo induce a reconocer al poitevino Picaud, al clérigo de Partenay-Le-Vieux» ${ }^{19}$.

O lugar natal deste poitevino, Aimerico Picaud, e hoxe cabeza do distrito no departamento de Deux-Sevres, no Poitou, ao oeste de Poitiers. Polo tanto, dentro da diócesis de cal fora bispo, San Venancio Fortunato, cinco séculos denantes do nacimento do casi seguro compilador e autor de moitos capítulos do Codex Calixtinus.

Mais, o tempo transcurrido, acaso porque os séculos discurrían entón sin moitas novedades literarias, non fixo esquencer aos cregos poitevinos a obra poética do seu máis inxel prelado. E Aimerico Picaud, sin dubida, a coñecía perfectamente, tal como se advirte na constante utilización dela no Liber Sancti Jacobi.

Por iso atribuéu tamén D. Abelardo Moralejo á mesma man os textos nos que aparecían tales copiosas citas de Venancio Fortunato. Quizaves esa man, insinúa D. Abelardo, fose «la del poitevino Aimerico Picaud, que figura entre los donantes del Códice». Esta hipótesis a desenrola o sabio profesor nunha extensa nota a sua versión do Liber Sancti Jacobi, na que indaga acerca da personalidade daquel "crego trotamundos, e da sua posible participación na escritura do Codex Calistinus: Analiza escuetamente nesa nota as diversas opinións dos grandes investigadores (Dozy, Pierre David, o P. Fita, René Louis, etc...) respecto ao compilador e a autoría do célebre códice?

Tras os pseudónimos eclesiásticos do Papa Calixto e do Arzobispo Turpin existiría, asegún os máis claros indicios, un xenial mixtificador: Aimerico Picaud, que pon os pés do Apóstol Santiago sua triple experiencia peregrina e sua excelente cultura latina. Singularmente o coñecemento da obra que aquel bispo da sua diócesis poitevina escribira medio milenio denantes. Tanto que lle permitía facer mangas e capirotes con ela; como mostraría o Dr. Moralejo nos seus discretísimos traballos, nos que pasa sobre ascuas no que atañe a precedencia de San Martiño de Tours e de San Martiño de Braga, no patrocinio e a evanxelización, respectivamente, dos galaicos. Anque nunca imaxinaría Aimerico Picaud, dende logo, que fose posible, no século XX, tan concienzuda e minuciosa labor investigadora dun catedrático zamorano de Santiago, que pusera a descu-berto as suas piadosas trapacerías poéticas ${ }^{18}$.

"CUADERNOS DE ESTUDIOS GALLEGOS", Tomo XLVI, Fascículo 111, Santiago 1999. 


\section{AS VINCULACIÓNS TURONENSES}

Ata aquí chego sin outra pretensión, neste mero e virtual ensaio histórico, que a de chamar a atención dos xóvenes medievalistas galegos acerca da misteriosa, ou arcana, vinculación da iglesia galega ca de Tours, dende moito máis atrás dos tempos merovingios, xa naqueles anos oscuros do burato negro da nosa Historia. Serían temas moi adrede pra investigar en futuras tesis doctorales os puntos que me atrevo a suxerir, por ter unha trascendencia extraordinaria na verdadeira, e non na ficticia, historia de Galicia:

$1^{\circ}$. Examinar a antiquísima relación da ciudad episcopal francesa de Tours con Galicia, moi anterior a Invención da Tumba de Santiago e que prosigue, con moi curiosas manifestacións, despóis.

$2^{\circ}$. Investigar as posibilidades de que a circunstancia de que fora San Martiño turonense o máximo valedor de Prisciliano no infame xuicio de Tréveris (polo que se condenóu a morte ao primer mártir do cristianismo heterodoxo, executado polos propios cristiáns), poido suscitar as simpatías dos priscilianistas galegos, hacia o santo bispo de Tours, e explicar así o seu antigo e extensísimo culto no noso país. Sendo, coma é ben sabido, o patrocinio de San Martiño, o máis abondoso nas feligresías galegas; existindo incluso unha ermita adicada a él, preto de San Fiz de Solobio, denantes de que se inventara alí a Tumba do Apóstol Santiago.

$3^{\circ}$. Esclarecer e afondar no contido da célebre carta de Alfonso III o Magno ao clero e pobo de Tours, datada arredor do ano 900. Nela, asegún Murguía, o rei asturiano confirma a existencia no templo ourensán das reliquias de San Martiño: «Sancta confesore Martini quorum reliquia sancta sunt in Ecclesia Auriensis, sedir Provinciae Galletiae...» ${ }^{4}$.

Este párrafo que o gran polígrafo de Galicia tomóuno, seguramente, da España Sagrada, do P. Flórez, foi eliminado logo da transcripción que fixo López Ferreiro da Carta de Alfonso III ${ }^{20}$. Ademáis, D. Manuel Murguía destacaba que Alfonso III lembra na sua carta a antigua irmandade da Iglesia de Tours ca de Orense, lexendariamente ligadas polo común padroazgo de San Martiño. Motivo posiblemente para causar o rece- 
lo do bo coengo compostelán, tan celoso pola preeminencia da sede xacobea.

A extraordinaria misi va do magno rei de Asturias e Galicia é un documento de enorme interés pra historia da nosa Alta Edad Media e a leenda xacobea; tendo seu claro antecedente na tan asendereada, por mín, Epístola Leonis. E, por si fose pouco, seu asunto xira arredor da posible venta a Alfonso III, por parte dos cregos de Tours, de certa coroa imperial. Polo que tería relación, quizaves, esta negociación ca cuestión da titularidad imperial que tantos quebradeiros de cachola ven causando aos máis inxels medievalistas ${ }^{21}$.

Madrid, Nadal do 1997

\section{NOTAS}

' TORRES RODRÍGUEZ, Casimiro. El reino de los suevos. Galicia Histórica preparada por el Instituto «P. Sarmiento» de Estudios Gallegos. Fundación Barrié de la Maza. La Coruña, 1977.

${ }^{2}$ RISCO, Vicente. Manual de Historia de Galicia. Editorial Galaxia. Vigo, 1952.

${ }^{3}$ PEDRET CASADO, Paulino. Introducción a la Traducción galega da obra de San Martiño de Braga 'De correctione rusticorum'. Nos, Bolétín mensual da Cultura Galega, ano 1932. Tomo V. No 97. Edición facsimilar de Galaxia. Vigo, 1979.

${ }^{4}$ MURGUÍA, Manuel. Galicia. Cap. VII. Edicións Xeráis de Galicia. Vigo, 1982.

${ }^{5}$ MACÍAS, Marcelo. «Panegírico de San Martín de Tours, patrono de la ciudad y diócesis de Orense, pronunciado en la S.I. Catedral, el día 11-XI-1891». En Aportaciones a la Historia de Galicia. Biblioteca de Estudios Gallegos. CIAP, Madrid, s/f.

${ }^{6}$ MENÉNDEZ PELAYO, Marcelino. Historia de los Heterodoxos Españoles (nueva edición con notas inéditas). Tomo I. C.S.I.C. Santander, 1946.

${ }^{7}$ Liber Sancti Jacobi. Codex Calixtinus. Traducción por los Profrs. A. Moralejo, C. Torres y J. Feo. Dirigida, prologada y anotada por el primero. C.S.I.C. Instituto Padre Sarmiento de Estudios Gallegos. Santiago de Compostela, 1951.

${ }^{8}$ LÓPEZ PEREIRA, Xosé Eduardo. Cultura, Relixión e Supersticións na Galicia Sueva. Edición, Traducción e Comentario do libro de Martiño de Braga De correctione rusticorum. Universidade da Coruña. Servicio de Publicacións, 1996. Nesta obra, publicada sesenta e catro anos máis tarde que a primeira versión ao galego, feita por D. Paulino Pedret en Nos, asegura López Pereira estar «en condicións de darlle un volco a esta opinión xeneralizada desde Enrique Flórez, na sua España Sagrada», respecto a que San Martín Dumiense era nado na Panonia. O ilustre latinista de Trasalba argumenta sobre catro textos de outros tantos santos autores (o propio Dumiense, Venancio Fortunato, Gregorio de Tours e Isidoro de Sevilla), pra apuntar a tesis de que San Martiño o Novo, aun sendo panonio de orixen, cecáis nacera en Italia, e «chegóu posiblemente (a Galicia) desde o Sur da Galia».

"CUADERNOS DE eSTUdiOS GALLEGOS", Tomo XLVI, Fascículo 111, Santiago 1999. 
${ }^{9}$ IGLESIA ALVARIÑO, Aquilino. Versión galega de Galiciense Carmen, de Venantii Fortunati. Tributo pontevedrés al Congreso Bracarense al XIV Centenario de San Martín de Dume. Gráficas Torres. Pontevedra, 1950. Aquilino, nesta versión libre do Carmen de San Venancio, traduce así o testimonio déste sobre a naturaleza do Dumiense:

$$
\begin{aligned}
& \text { El ven, según nos dín, de nobres } \\
& \text { castas da Panonia, pero eu mellor dixera } \\
& \text { que é a salvación Galaico-Sueva agora. }
\end{aligned}
$$

${ }^{10}$ OTERO PEDRAYO, Ramón. Ensayo histórico sobre la Cultura Gallega. Publicado co falaz título de Historia de la Cultura Gallega, por Emece Editores. Buenos Aires, 1939.

"IGLESIA ALVARIÑO. ob. cit. Aquilino traduce libre e ledamente a estrofa enteira do santo bispo de Poitiers:

$$
\begin{aligned}
& \text { Pra decilo, nun credo, madrugueira } \\
& \text { seguíu a Galia de Martiño o Vello, } \\
& \text { cunha fe que non sei, o craro bando. } \\
& \text { Mais ti agardabas por Martiño o Novo: } \\
& \text { Galicia, os teus aprausos ora soen. } \\
& \text { No sorteo apostólico, Martiño } \\
& \text { de certo che caéu. }
\end{aligned}
$$

${ }^{12}$ LÓPEZ ALSINA, Fernando. La ciudad de Santiago de Compostela en la Alta Edad Media. Centro de Estudios Jacobeos, Santiago de Compostela, 1988.

${ }^{13}$ IGLESIA ALVARIÑO. ob. cit. Aquilino no exemplar do Carmen que adicóu o Borobó, escribe graciosamente: «San Venancio era un santiño do norte de Italia, moi gasalleiro, poeta e bebedor a sorbos pequeniños. Cando chegaba a noite, dinos el que non daba cadillado un novelo que selle desencadillaba na cabeza».

${ }^{14}$ MORALEJO LASO, Abelardo. «Sobre el sentido de unos versos de Venancio Fortunato a San Martín Dumiense en relación con la tradición jacobea». Compostellanum. Sección de Estudios Jacobeos. Vol. III, N 4, pp. 341-347, Santiago de Compostela, 1958.

${ }^{15}$ IGLESIA ALVARIÑO. ob. cit. Aquilino traduce «ne mores acelerans», como xa consta na nota 13, cun sintagma moi católico: «Pra decilo nun credo». O tempo que leva pasar un ovo por auga.

${ }^{16}$ BOROBÓ. «Aquel dístico de Venancio Fortunato». A Nosa Terra, 30-X-1997, No 802. Oleastro é un vocablo romance, sinónimo do arábigo español acebuche.

${ }^{17}$ Versión libre de Borobó, aproveitando moitas palabras do belido léxico de Iglesia Alvariño.

${ }^{18}$ MORALEJO LASO, Abelardo. «Las citas poéticas de S. Fortunato en el Códice Calixtino». Cuadernos de Estudios Gallegos, fasc. XIV, pp. 349-366. Santiago de Compostela, 1949.

${ }^{19}$ VÁZQUEZ DE PARGA, Luis; LACARRA, José M.; URÍA RIU, Juan. Las peregrinaciones a Santiago de Compostela. Tomo I, parte 2a, capítulo I. Edición facsimil realizada por el C.S.I.C. en 1948. Gobierno de Navarra. Pamplona, 1992.

${ }^{20}$ LÓPEZ FERREIRO, Antonio. Historia de la S.A.M. Iglesia de Santiago de Compostela. Tomo II, apéndice XXVII. Imprenta del Seminario Conciliar Central. Santiago, 1899.

${ }^{21}$ GARCÍA GALLO, Alfonso. El Imperio Medieval Español. En Historia de Espa$\tilde{n} a$. Estudios publicados en la revista Arbor. Madrid, 1953.

"CUADERNOS DE ESTUDIOS GALLEGOS", Tomo XLVI, Fascículo 111, Santiago 1999. 